\title{
Cepharanthine and Curcumin inhibited mitochondrial apoptosis induced by PCV2
}

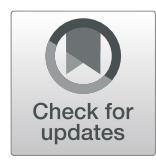

Yinlan $\mathrm{Xu}^{1 \dagger}$, Jiangang Zheng ${ }^{1 \dagger}$, Panpan Sun ${ }^{2}$, Jianhua Guo ${ }^{3}$, Xiaozhong Zheng ${ }^{4}$, Yaogui Sun ${ }^{1}$, Kuohai Fan $^{2}$, Wei Yin ${ }^{1}$, Hongquan $\mathrm{Li}^{1 *}$ and Na Sun ${ }^{*}$

\begin{abstract}
Background: Porcine circovirus type 2 (PCV2) is an immunosuppressive pathogen with high prevalence rate in pig farms. It has caused serious economic losses to the global pig industry. Due to the rapid mutation of PCV2 strain and co-infection of different genotypes, vaccination could not eradicate the infection of PCV2. It is necessary to screen and develop effective new compounds and explore their anti-apoptotic mechanism. The 13 natural compounds were purchased, with a clear plant origin, chemical structure and content and specific biological activities.

Results: The maximum no-cytotoxic concentration (MNTC) and 50\% cytotoxic concentration (CC 50 ) of 13 tested compounds were obtained by the cytopathologic effect (CPE) assay and (3-(4,5-dimethyithiazol-2-yl)-2,5diphenyltetrazolium bromide (MTT) method in PK-15 cells. The results of qPCR and Western blot showed that, compared with the PCV2 infected group, the expression of Cap in Paeonol $(0.4 \mathrm{mg} / \mathrm{mL}$ and $0.2 \mathrm{mg} / \mathrm{mL})$, Cepharanthine $(0.003 \mathrm{mg} / \mathrm{mL}, 0.0015 \mathrm{mg} / \mathrm{mL}$ and $0.00075 \mathrm{mg} / \mathrm{mL})$ and Curcumin $(0.02 \mathrm{mg} / \mathrm{mL}, 0.001 \mathrm{mg} / \mathrm{mL}$ and $0.005 \mathrm{mg} / \mathrm{mL})$ treated groups were significantly lowered in a dose-dependent manner. The results of Annexin V-FITC/PI, JC-1, Western blot and ROS analysis showed that the expression of cleaved caspase-3 and Bax were up-regulated BCl-2 was downregulated in Cepharanthine or Curcumin treated groups, while ROS and MMP value were decreased at different degrees and the apoptosis rate was reduced. In this study, Ribavirin was used as a positive control.
\end{abstract}

Conclusions: Paeonol, Cepharanthine and Curcumin have significant antiviral effect. And the PCV2-induced Mitochondrial apoptosis was mainly remitted by Cepharanthine and Curcumin.

Keywords: PCV2, Cap, Paeonol, Cepharanthine, Curcumin, Apoptosis

\section{Background}

PCV2 is a DNA virus, which is an important pathogen causing high infection rate and immunosuppression in pigs [1]. The diseases caused by PCV2 mainly include postweaning multisystemic wasting syndrome (PMWS), Porcine dermatitis and nephropathy syndrome (PDNS), Porcine proliferative and necrotizing pneumonia (PNP), etc., which have caused serious economic losses to the global pig industry for about 57 years [2]. The capsid

\footnotetext{
*Correspondence: livets@163.com; snzh060511@126.com

†Yinlan Xu and Jiangang Zheng contributed equally to this work.

${ }^{1}$ College of Veterinary Medicine, Shanxi Agricultural University, Taigu, Shanxi 030801, China

Full list of author information is available at the end of the article
}

protein (Cap) encoded by the ORF2-encoded gene of PCV2 is a major viral structural protein and an immunogen involving viral replication of PCV2 [3]. Studies have shown that PCV2 could induce apoptosis and decrease spleen lymphocytes in immune organs of BALB/c mice and pigs $[4,5]$ and apoptosis can be induced through endoplasmic reticulum (ER) apoptosis, mitochondrial apoptosis, reactive oxygen species (ROS) regulation, etc. [6-9].

It has been reported that vaccination could not eradicate the infection of PCV2, due to the rapid mutation of PCV2 strain and co-infection of different genotypes, etc. $[10,11]$. Therefore, it is needed to control infection. Chinese herbal medicine has the characteristics of high 
efficiency, low toxicity and low residue. It can improve the immunity, possess anti-stress and anti-virus ability. A variety of natural compounds or their active ingredients have been used to enhance host immune, prevent and treat viral diseases, such as Coronavirus diseases [12], Hepatitis B (HB) [13], Infectious bronchitis [14], African swine fever (ASF) [15], Influenza [16] and other viral diseases. However, the research on the anti-PCV2 action of natural compounds and its mechanism has also become a hotspot.

In our previous studies, dozens of natural compounds were screened for their antiviral activity, such as Chlorogenic Acid [17], ligustrazine hydrochloride [18], Scutellarin [17, 19], dipotassium glycyrrhizinate $[18,20,21]$, Sodium tanshinone IIA sulfonate [21, 22], tea seed saponins [23] and Matrine [19, 24, 25]. Among them, only Scutellarin or Matrine had antiPCV2 effect [19, 25].

Therefore, in this study, from many natural compounds with clear chemical structure, traditional medicine plant source and specific biological activity, 13 compounds with antiviral potential were selected and tested in the model of PCV2 infected PK-15 cell to screen anti-PCV2 compounds in vitro. Furthermore, the potential antiviral mechanism of compounds was explored and explained from the perspectives of apoptosis, mitochondrial membrane potential (MMP) and ROS. It provides a theoretical basis for the development of a safely, efficiently new compound with anti-PCV2 effect.

\section{Results}

Cytotoxicity of 13 compounds on the PK-15 cells detected by MTT

Compared with the normal group of normal cells, the results showed that (See Additional file 1), the degree of cytopathological change were also different after the treatment of different compounds and different concentrations of the same compound. Due to the low solubility, the maximum solubility concentration (MSC) of 0.8 $\mathrm{mg} / \mathrm{mL}$ Formononetin, $0.8 \mathrm{mg} / \mathrm{mL}$ Icariine and $0.15 \mathrm{mg} /$ $\mathrm{mL}$ Astragaloside were used to treat the cells, respectively and no change in cell morphology was observed. The MNTC is the same as MSC. The 10 compounds except Formononetin, Icariine and Astragaloside showed different cytopathic changes (see Additional file 1) and MNTC values (Table 2). Dose-response curves of the tested compounds (Fig. 1) and $\mathrm{CC}_{50}$ value (Table 2) were generated by GraphPad Prism 5.0 analysis after calculating the $C R$ value. The curves were " $\mathrm{S}$ " type, showing a dose-dependent relationship. As the concentration of the compound increased, more cells with change in morphology the was observed.

\section{The anti-PCV2 effect of Paeonol, Cepharanthine and Curcumin}

To explore the anti-PCV2 effect of compounds, the expression levels of Cap was detected by qPCR and Western blot. The results of qPCR showed that, compared to cell control group, the PCV2 copy numbers were significantly increased $(P<0.05)$, compared to PCV2 infected group, the PCV2 copy numbers were significantly decreased in these compound treated with Formononetin at 0.8, Icariine at 0.8 , Paeonol at $0.4,0.2$ and $0.1 \mathrm{mg} / \mathrm{mL}$, Cepharanthine at $0.003,0.0015$ and $0.00075 \mathrm{mg} / \mathrm{mL}$, Curcumin at 0.02, 0.01 and $0.005 \mathrm{mg} / \mathrm{mL}$, Curcumol at 0.024 and Syringin at 0.625 and $0.3125 \mathrm{mg} / \mathrm{mL}(P<0.05)($ Fig. $2 \mathrm{a})$.

Based on the results by qPCR, dose-dependent Paeonol, Cepharanthine and Curcumin were selected for Western blot. The results showed that the expression level of Cap protein treated with the three compounds respectively were significantly lower than PCV2 infected group $(P<0.05)$, except the $0.1 \mathrm{mg} / \mathrm{mL}$ of Paeonol group (Fig. 2b) (For original and unedited blots see Additional file 2). Therefore, the Cepharanthine and Curcumin were selected for the subsequent anti-apoptotic test.

\section{Inhibition of PCV2-induced apoptosis by Cepharanthine and Curcumin}

To evaluate the anti-apoptosis effect of Cepharanthine or Curcumin, Samples were analyzed after being treated with Annexin V/PI by Flow cytometer. The results showed that Compared to the PCV2-infected group, the cell apoptosis rates were significantly decreased in the group treated with Cepharanthine, Curcumin or Ribavirin, demonstrating a dose-dependent response except the group of $0.005 \mathrm{mg} / \mathrm{mL}$ Paeonol $(P<0.05)$ (Fig. 3a and $b)$. Our results indicated that Cepharanthine, Curcumin or Ribavirin could significantly inhibit PCV2induced apoptosis $(P<0.05)$.

\section{Inhibition of PCV2-induced apoptosis by Cepharanthine and Curcumin via the mitochondria pathway}

To evaluate the anti-apoptosis mechanism of Cepharanthine or Curcumin, Samples were analyzed after being treated with JC-1 kit by Flow cytometer. The results showed that Compared to the PCV2-infected group, the MMP value were significantly decreased in the group treated with Cepharanthine, Curcumin and Ribavirin, demonstrating a dose-dependent response $(P<0.05)$ (Fig. 4a and b). The results indicated that Cepharanthine, Curcumin or Ribavirin could significantly inhibit PCV2induced apoptosis via mitochondrial pathway $(P<0.05)$.

\section{The mechanism of inhibition of PCV2-induced} mitochondrial apoptosis by Cepharanthine and Curcumin To evaluate the mechanism of inhibition of PCV2induced mitochondrial apoptosis by Cepharanthine or 


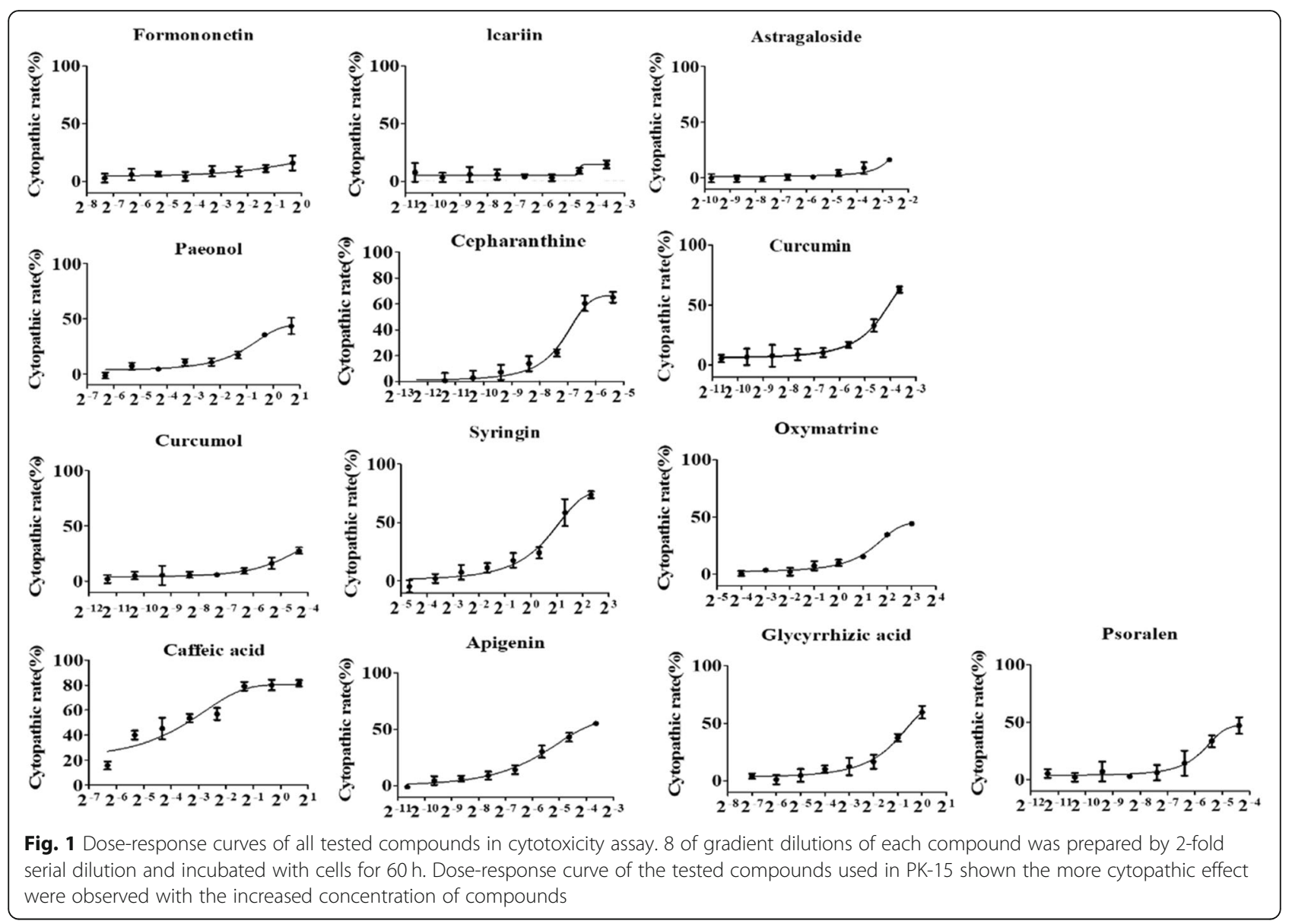

Curcumin, Samples were analyzed by Western blot and Flow cytometer. The results of Western blot showed that Compared with the PCV2-infected group, the expression of pro-apoptin cleaved caspase- 3 and Bax was significantly decreased while the expression of antiapoptotic protein $\mathrm{Bcl}-2$ was significantly increased in the treatment group of Cepharanthine, Curcumin or Ribavirin (Fig. 5a-h) (The original and unedited blots see Additional file 2). The results of Flow cytometer after being stained with ROS kit demonstrated that the value of ROS in the Curcumin-treated group showed strongly downward trend in a dose-dependent manner, compared with the PCV2 control group (Fig. 5i and j). However, only the group of treated with $0.003 \mathrm{mg} / \mathrm{mL}$ of Cepharanthine could significantly reduce the amount of ROS $(P<0.05)$. The results demonstrated that Cepharanthine or Curcumin inhibited the PCV2induced increase in MMP through the caspase family and Bcl-2 family mechanisms. Curcumin inhibited PCV2-induced mitochondrial apoptosis by reducing ROS, However, ROS reduction is not the main pathway for Cepharanthine and Ribavrin to inhibit PCV2induced mitochondrial apoptosis.

\section{Discussion}

PCV2 is the main pathogen causing porcine circovirus associated diseases (PCVAD). In this study, 13 natural compounds with defined chemical structures, useful clinical effect and from medicinal plants were selected. After the primary screening, three compounds with antiviral effect, Paeonol, Cepharanthine and Curcumin were further studied. The anti-apoptotic mechanism of these two compounds was investigated by evaluating the level of key apoptins, MMP and ROS in the cellular mitochondrial pathway. Ribavirin has a broad antiviral activity and was used as a positive control.

Cepharanthine is a natural alkaloid extracted from the roots of the Stephania japonica, which has antiinflammatory [26], anti-Hepatitis B virus [27], herpes simplex type-1 virus (HSV-1) [28] and etc. Curcumin is an active ingredient extracted from the rhizome of some plants of the Zingiberaceae and Araceae. Medical research shows that curcumin has low toxicity, little adverse reactions and multiple therapeutic effects, such as anti-inflammatory [29], anti- oxidative [30], anti-H9N2 influenza virus [31], dengue virus [32], hepatitis $C$ virus [33] and so on. 


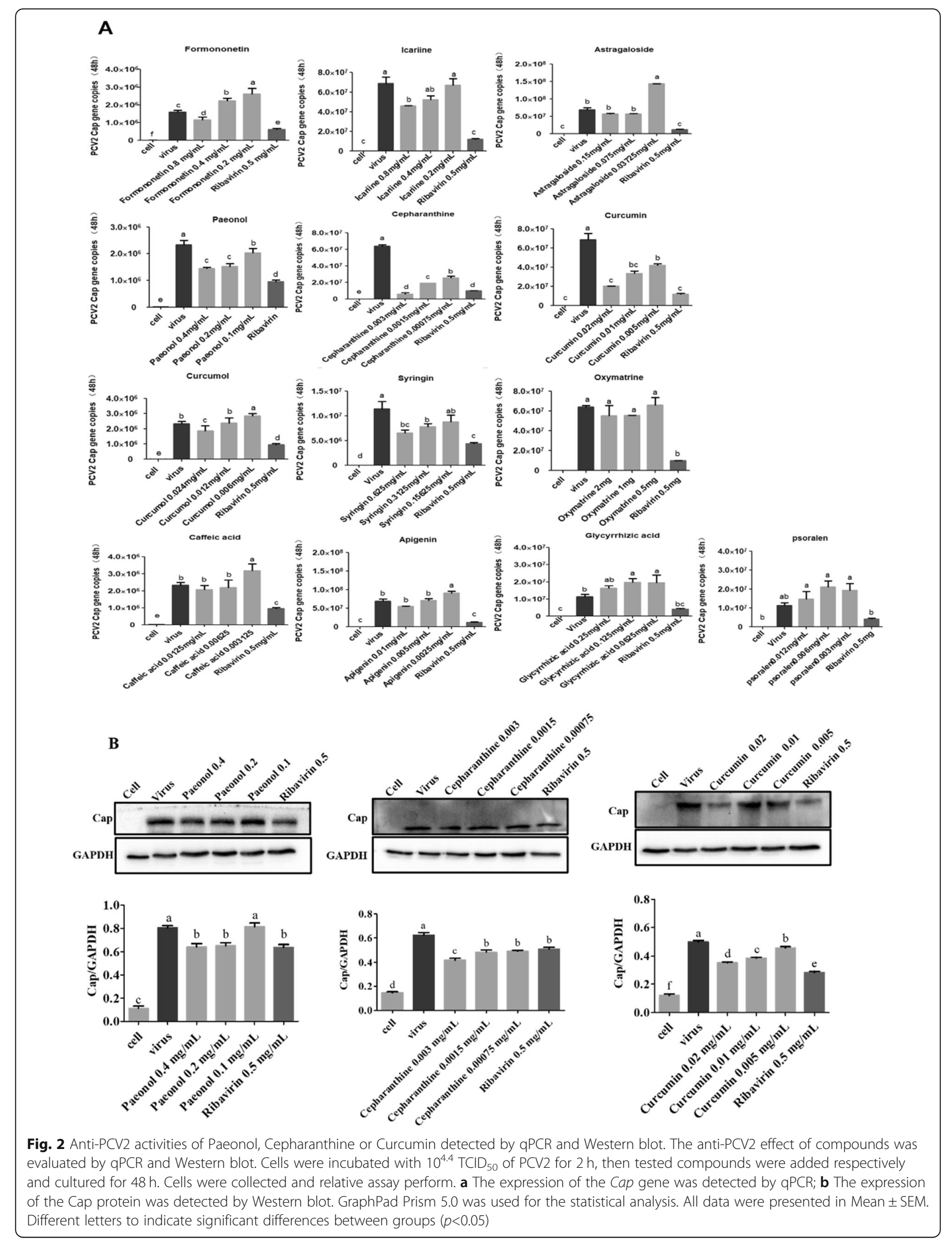




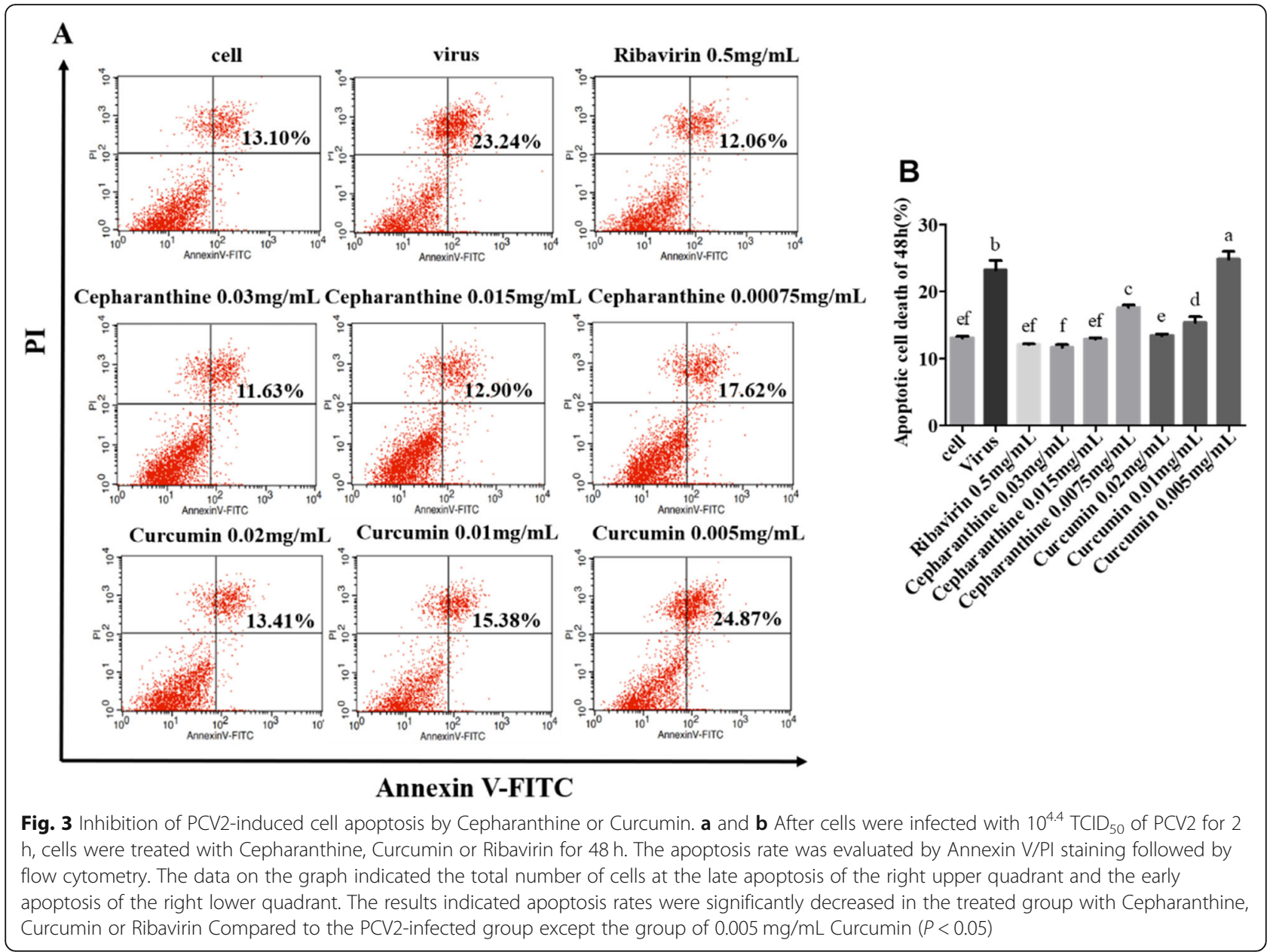

Zhang et al. demonstrated that PCV2 Cap could induce mitochondrial apoptosis of PK-15 and PAM cells by interfering with $\mathrm{Ca}^{2+}$ homeostasis, down-regulating MMP and increasing intracellular ROS [7]; Lin et al. found that PCV2 induced mitochondrial apoptosis of PCV2 infected PK-15 cells and $293 \mathrm{~T}$ cells by increasing the activities of caspase- 3 and caspase- 9 and accelerating the release of cytochrome $\mathrm{C}$ (Cyto $\mathrm{C}$ ) from mitochondria to cytoplasm [34]; After PCV2 infected RAW264.7 cells, stress-related molecules such as ROS production and NO secretion were significantly increased [35]; Previous studies have shown that PCV2 infection promotes the accumulation of ROS, which in turn inhibits the replication of PCV2 through the NF- $\mathrm{BB}$ pathway [36]. Therefore, we hypothesized that the experimental compounds could inhibit the mitochondrial apoptosis of PK-15 cells induced by PCV2 infection via acting on mitochondrial membrane potential. Mitochondria have a central role in cell apoptosis. The loss of MMP is the marker of mitochondrial apoptosis, the changes of MMP are caused by Bcl-2 family, Caspase family and Miochondrial permeability transition pore (MPTP) [37]. Cleaved caspase-3 is the main executive protein of apoptosis. There are many members of the Bcl-2 family, among which Bax is the main pro-apoptotic protein and $\mathrm{Bcl}-2$ is the main antiapoptotic protein. The opening and closing of MPTP is influenced by $\mathrm{ROS}, \mathrm{Ca}^{2+}$, ADP, oxidative stress, high $\mathrm{PH}$ value and other apoptotic factors [37]. In this study, at first, the cell apoptosis and change of MMP were detected by flow cytometry after Annexin V/PI double staining and $\mathrm{JC}-1$ assay. The results indicated that Cepharanthine, Curcumin or Ribavirin could significantly inhibit PCV2-induced apoptosis via mitochondrial pathway. To further evaluate the mechanism of Cepharanthine or Curcumin inhibiting mitochondrial apoptosis, the apoptins of Caspase family and Bcl-2 family were analyzed by Western blot, the values of ROS were analyzed by flow cytometry after ROS kit staining. The results showed that Compared with cell control group, the expression levels of cleaved caspase- 3 and Bax were upregulated, and the expression of $\mathrm{Bcl}-2$ was downregulated, the ROS values are increased. This result is consistent with the previous reports [6,34, 38]. Compared with PCV2-infected group, the expression levels of 


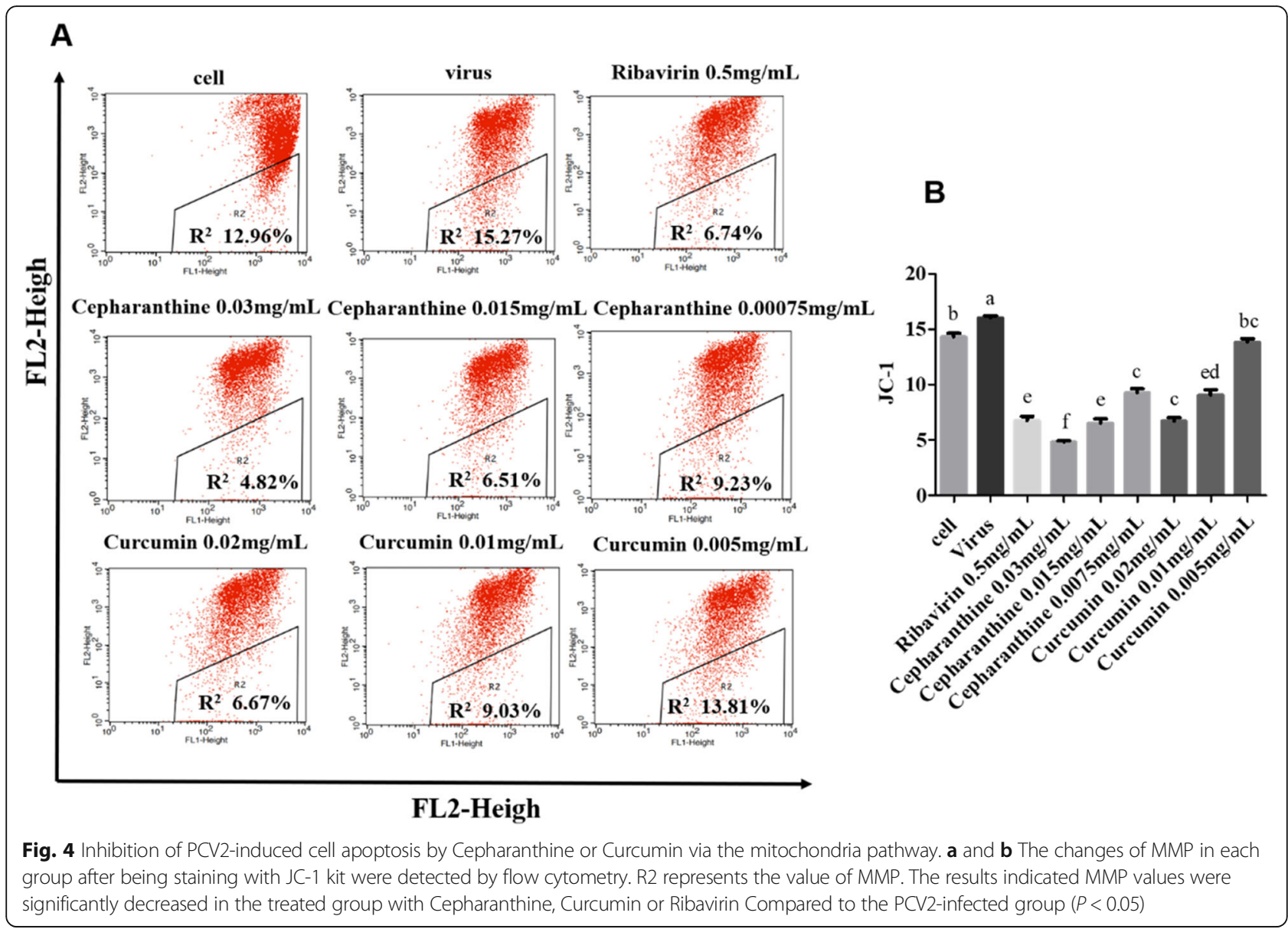

cleaved caspase- 3 and Bax were down-regulated, and the expression of $\mathrm{Bcl}-2$ was up-regulated in the treated with Cepharanthine or Curcumin. The value of ROS was decreased but ROS did not decrease in treated with the 0.0015 and $0.00075 \mathrm{mg} / \mathrm{mL}$ of Cepharanthine. The results demonstrated that Cepharanthine or Curcumin inhibited the PCV2-induced increase in MMP through the caspase family and $\mathrm{Bcl}-2$ family mechanisms. Curcumin could inhibit cell mitochondrial apoptosis by regulating the opening of MPTP through reducing the level of ROS, but Cepharanthine and Ribavirin did not have the similar effect. It is speculated that various antiviral compounds could inhibit the cell apoptosis by governing MMP through affecting mitochondrial apoptosis pathway.

\section{Conclusion}

To summarize, our study revealed that Paeonol, Cepharanthine and Curcumin have significant antiviral effect, and Cepharanthine and Curcumin could inhibit PCV2induced mitochondrial apoptosis by through change the MMP (Fig. 6). The study provides a base line for further studies on the anti-PCV2 effect and anti-apoptosis mechanism of Cepharanthine and Curcumin in experimental animal models infected with PCV2, and may be applied in clinical treatment as anti-virus compounds eventually.

\section{Methods}

Cells, viruses, antiboties and nature compounds

PCV-free pig kidney endothelial cell line (PK-15) was preserved in our laboratory. Cells were cultured and passed in Dulbecco's modified eagle's medium (DMEM, Hyclone, USA) containing 10\% fetal calf serum (FBS, BI, Israel) (10\% DMEM) and maintenance in DMEM containing $2 \%$ FBS (2\% DMEM).

The strain of PCV2-SH (GenBank: AY686763.1) was gifted by Professor Jiang Ping of Nanjing Agricultural University. Virus was replicated and harvest in PK-15 cells infected with PCV2. The titer of $10^{6.4} \mathrm{TCID}_{50} / \mathrm{mL}$ was determined by Indirect Immunofluorescence (IFA).

Antibodies against Cap were purchased from Biorbyt LLC. (California, Britain) cleaved caspase-3, Bcl-2 and Bax were purchased from Abcam (Cambridge, USA); GAPDH and horseradish peroxidase (HRP)-conjugated secondary antibodies were purchased from Wuhan Sanying Biology Technology Co., Ltd. (Wu Han, China). 


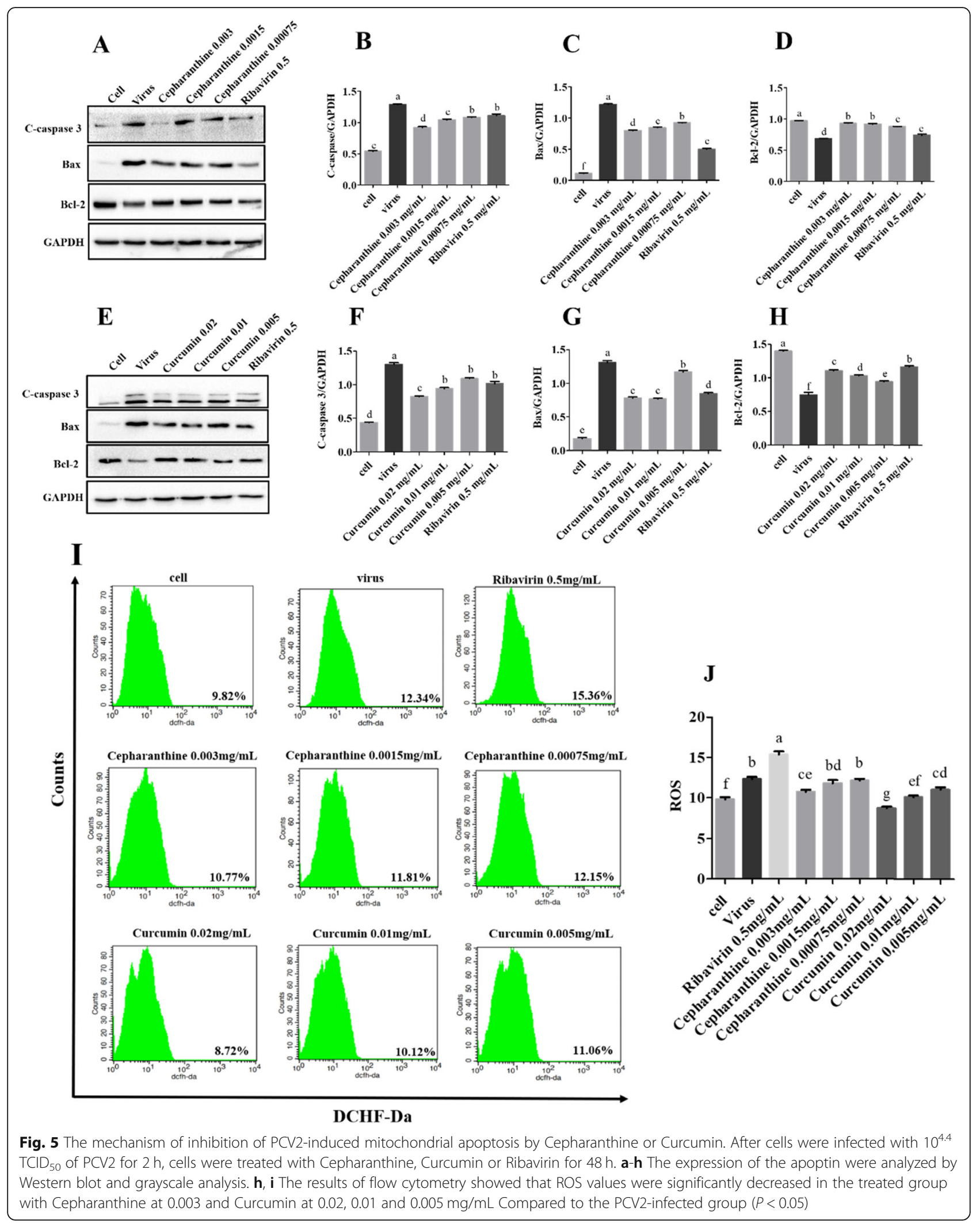




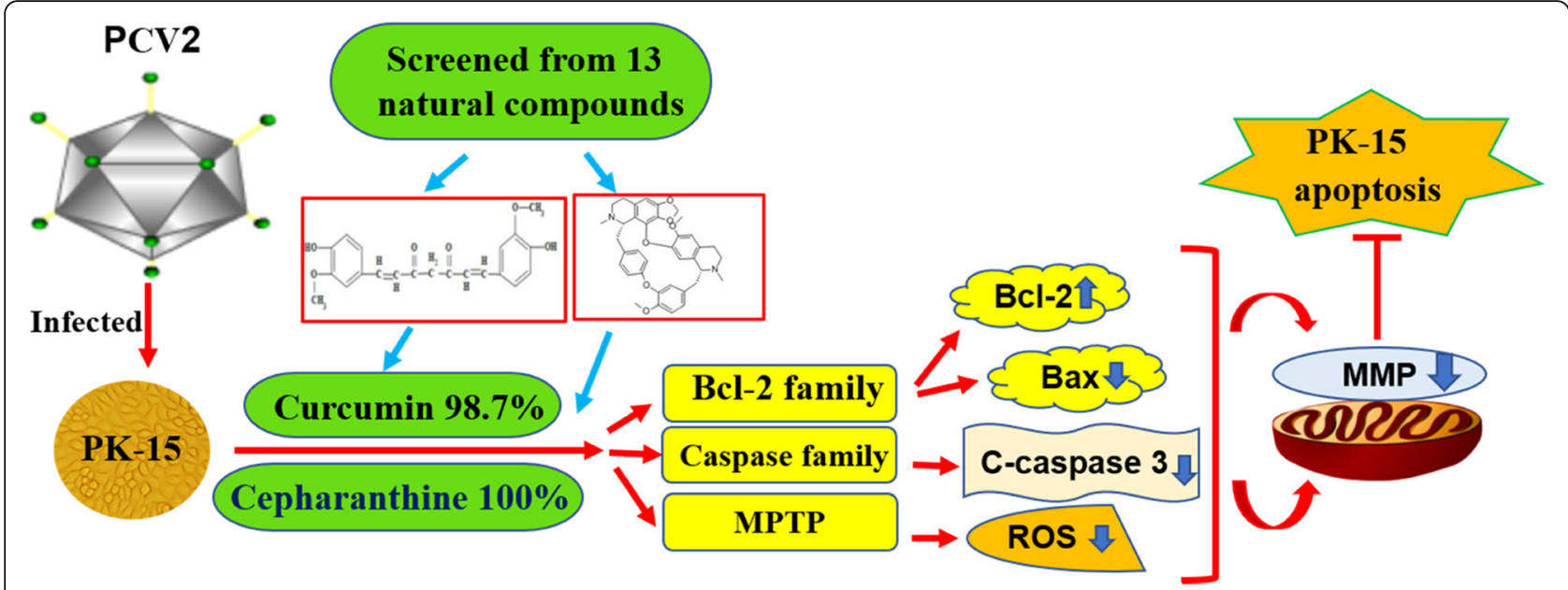

Fig. 6 The PCV2-induced Mitochondrial apoptosis was mainly remitted by Cepharanthine and Curcumin. The "red arrow" represents the promoting effect and the red "T-shape" indicates the inhibiting effect. The PCV2 replication is inhibited by Cepharanthine and Curcumin, selected from 13 natural compounds, through mitochondrial apoptosis pathway

Ribavirin, the positive control drug, was purchased from Beijing Solarbio technology co., LTD; Syringin was purchased from Nanjing Puyi biotechnology co., LTD; Glycyrrhizin aid was purchased from DOSF biotechnology co., LTD; Other tested compounds, such as Curcumol, Paeonol, Oxymatrine, Caffeic acid, Formononetin, Cepharanthine, Apigenin, Psoralen, Lcariine, Curcumin and Astragaloside were purchased from National Institutes for Food and Drug Control. Compounds information and chemical structure were respectively listed Table 1 and Fig. 7.

\section{Cytotoxicity assay}

The viability of PK-15 cell was assessed with MTT. $1.0 \times 10^{6}$ cells $/ \mathrm{mL}$ of cells were seeded into 96-well plates and incubated until $100 \%$ confluency was reached. The tested compounds were added with two-fold serial diluted and cultured for another $60 \mathrm{~h}$ and cell control group was established. Four repeated wells were set up for each concentration with $100 \mu \mathrm{L}$ per well. The cytopathic condition of cells was observed every day and photographed. The compounds and dissolution methods are shown in Table 1 . Then $25 \mu \mathrm{L}$ MTT $(4 \mathrm{mg} / \mathrm{mL}$ in PBS) was added to each well and incubated at $37^{\circ} \mathrm{C}$ for 4h. $150 \mu \mathrm{L}$ of DMSO (Solarbio, Beijing) was added and incubated for $30 \mathrm{~min}$ after removing the culture medium. The optical density (OD) were measured at $490 \mathrm{~nm}$ using a microplate spectrophotometer (Spectra Max M5, Molecular Devices, USA). Cytopathic ratio (CR) was calculated based on $\mathrm{CR}=[(\mathrm{OD}$ control - OD test)/ OD] $\times 100$. Then MNTC and $\mathrm{CC}_{50}$ on PK-15 cells were calculated using GraphPad Prism ${ }^{\text {Tw }} 5.0$ (Inc. California, USA).

\section{Real time quantitative PCR}

The anti-PCV2 effect of compounds in PK-15 cell was determined by real time quantitative PCR (qPCR). When cell confluency rate of 24 -well plate reached $80 \%, 10^{4.4}$ $\mathrm{TCID}_{50}$ of PCV2 was incubated for $2 \mathrm{~h}$ and discarded the supernatant. MNTC of every test compound was in two-fold serial dilution with 2\% DMEM into 3 gradients and added to 24-well plates $(500 \mu \mathrm{L} /$ well) (Table 2). Meanwhile, the cell control group, PCV2-infected group and Ribavirin positive control group were applied and incubated for $48 \mathrm{~h}$ with $5 \% \mathrm{CO}_{2}$ at $37^{\circ} \mathrm{C}$. DNA was extracted according to the instruction of DNA extraction kit (TianGen, Beijing, China) and the DNA concentration was measured using a nucleic acid concentration analyzer (NanoDrop Technologies, Wilmington, DE, USA). The copy number of the Cap gene was detected by qPCR. The Primers $5^{\prime}$ TAC ATT TCC AGC AGT TTG and 5'CTC CCG CCA TAC CAT AA were used for the amplification of $148 \mathrm{bp}$ fragment.

\section{Western blot}

The anti-PCV2 effect and anti-apoptotic mechanism of the compound was detected by Western blot. When cell confluency of 6 -well plate reached $80 \%, 10^{4.4} \mathrm{TCID}_{50}$ of PCV2 was incubated for $2 \mathrm{~h}$ and discarded the supernatant. Paeonol, Cepharaanthine and Curcumin were added in turn, $2 \mathrm{~mL} /$ well. The cell control group, PCV2infected group and Ribavirin positive control group were applied and incubated for $48 \mathrm{~h}$. Total cell protein was extracted and protein concentration was determined using the BCA protein assay kit (Beyotime Biotechnology, Jiangsu, China). The protein samples were separated by SDS-PAGE, then transferred to the PVDF membrane. The levels of PCV2 Cap protein and apoptin were 
Table 1 The compounds used in the test

\begin{tabular}{|c|c|c|c|c|c|}
\hline No. & Chemical name & Classification & Main plant source & Cosolvent & Purity \\
\hline 1 & Formononetin & Phenolic acids & Mango & 1\%DMSO & $98.10 \%$ \\
\hline 2 & Icariine & Flavonoid glycosides & Herba epimedii & 1\%DMSO & $94.20 \%$ \\
\hline 3 & Astragaloside & Saponins & Astragalus membranaceus & 1\%DMSO & $96.90 \%$ \\
\hline 4 & Paeonol & Monoterpenes & Peony & 1\%DMSO & $99.90 \%$ \\
\hline 5 & Cepharanthine & Alkaloide & Stephania & $1 \% \mathrm{DMSO}$ & $100.00 \%$ \\
\hline 6 & Curcumin & Polyphenols & Turmeric & 1\%DMSO & $98.70 \%$ \\
\hline 7 & Curcumol & Hemiketal & Curcuma zedoary & 1\%DMSO & $99.90 \%$ \\
\hline 8 & Syringin & Phenylpropanolides & Lilac & DMEM & $95.20 \%$ \\
\hline 9 & Oxymatrine & Alkaloid & Sophora & DMEM & $92.50 \%$ \\
\hline 10 & Caffeic acid & Organic acid & Caffeic & 1\%DMSO & $99.70 \%$ \\
\hline 11 & Apigenin & Flavonoid & Apium graveolens & 1\%DMSO & $99.20 \%$ \\
\hline 12 & Glycyrrhizic acid & Triterpenes & Glycyrrhiza & DMEM & $95.00 \%$ \\
\hline 13 & Psoralen & Furancoumarins & Fructus psoraleae & 1\%DMSO & $99.70 \%$ \\
\hline
\end{tabular}

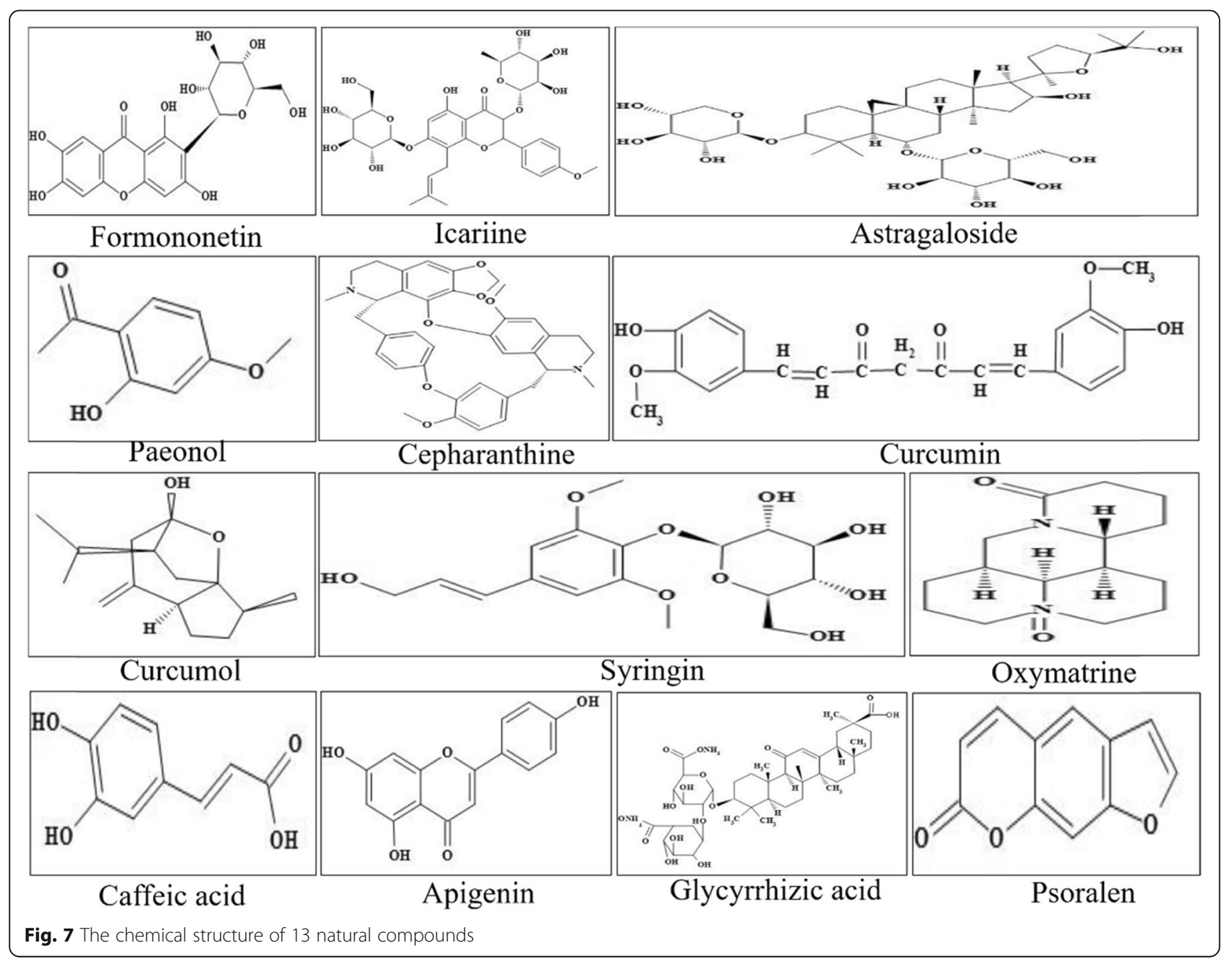


Table 2 The results of cytotoxicity

\begin{tabular}{llll}
\hline No. & Chemical name & MNTC $(\mathbf{m g} / \mathbf{m L})$ & $\mathbf{C C}_{\mathbf{5 0}}(\mathbf{m g} / \mathbf{m L})$ \\
\hline 1 & Formononetin & 0.8 & $>0.8$ \\
2 & Icariine & 0.8 & $>0.8$ \\
3 & Astragaloside & 0.15 & $>0.15$ \\
4 & Paeonol & 0.4 & $1.2696 \pm 0.08983$ \\
5 & Cepharanthine & 0.003 & $0.008048 \pm 0.0006136$ \\
6 & Curcumin & 0.02 & $0.06296 \pm 0.02424$ \\
7 & Curcumol & 0.024 & $0.115 \pm 0.02331$ \\
8 & Syringin & 0.625 & $1.128 \pm 0.5339$ \\
9 & Oxymatrine & 2 & $8.31 \pm 0.3896$ \\
10 & Caffeic acid & 0.0125 & $0.2581 \pm 0.07863$ \\
11 & Apigenin & 0.01 & $0.04817 \pm 0.01821$ \\
12 & Glycyrrhizic acid & 0.25 & $0.7162 \pm 0.04979$ \\
13 & Psoralen & 0.012 & $0.05549 \pm 0.01850$ \\
\hline
\end{tabular}

detected using an eECL Western Blot detection kit (Cwbio Inc., Beijing, China) and chemiluminescence imaging system (BIO-RAD, California, USA).

\section{Annexin V/PI staining for apoptosis}

The anti-apoptotic effect of Cepharaanthine and Curcumin were detected by Annexin V/PI. Cells in 6-well plate were incubated with $10^{4.4}$ TCID $_{50}$ of PCV2 for $2 \mathrm{~h}$ and discarded the supernatant, then Cepharaanthine and Curcumin were added, the cell control group, PCV2infected group and Ribavirin positive control group were applied and incubated for $48 \mathrm{~h}$. Samples were collected, centrifugated and treated using Annexin V/PI kit (Keygen Biotech, Nanjing, China), then analyzed by flow cytometry (BD Biosciences, USA).

\section{Detection of MMP by JC-1}

Mitochondrial membrane potential (MMP) of cells was detected by JC-1. Cells in the 6-well plate were incubated with $10^{4.4} \mathrm{TCID}_{50}$ of PCV2 for $2 \mathrm{~h}$ and discarded the supernatant, then Cepharaanthine and Curcumin were added. After $48 \mathrm{~h}$ incubation, cells were stained with JC-1 using a commercial kit (Beyotime Biotechnology, Jangsu, China) treated and analyzed by flow cytometry (BD Biosciences, USA).

\section{Detection of ROS by flow cytometer assay}

The amount of reactive oxygen species (ROS) was measured by flow cytometry. Cells in the 6-well plate were incubated with $10^{4.4}$ TCID $_{50}$ of PCV2 for $2 \mathrm{~h}$ and discarded the supernatant, Cepharaanthine and Curcumin were added and incubated for $48 \mathrm{~h}$. Cells were treated with ROS assay kit and the changes of ROS were detected by Flow cytometer.

\section{Statistical analysis}

$\mathrm{CC}_{50}$ was calculated using nonlinear regression and the results of "log (inhibitor) vs. response-variable slope" were analyzed using GraphPad Prism. The gray intensity of protein bolts was analyzed by Image J (National Institutes of Health, USA). Data generated were analyzed using "Bonferroni: Compare all pairs of columns" in the GraphPad Prism $^{\text {тм }} 5.0$ software for one-way ANOVA implemented (GraphPad Software, Inc. California, USA), and were expressed as the mean \pm standard error of the mean (SEM) of at least 3 repeated experiments. Different letters (a, b, c, d, etc.) indicate statistically significant difference to other groups $(p<0.05)$.

\section{Supplementary information}

Supplementary information accompanies this paper at https://doi.org/10. 1186/s12917-020-02568-0.

Additional file 1. Original microscopic images of Cytotoxicity of 13 compounds on PK-15 cells.

Additional file 2. Original blot images of Fig. 2a, Fig. 5a and e. (a-f) Original blot images of Cap and GAPDH in the Fig. 2a, respectively. ( $g-j$ ) Original blot images of cleaved caspase-3, Bcl-2, Bax, and GAPDH in the Fig. $5 a$, respectively. ( $k-n)$ Original blot images of cleaved caspase-3, Bcl-2, Bax, and GAPDH in the Fig. 5e, respectively.

\section{Abbreviations}

PCV2: Porcine circovirus type 2; PK-15: PCV-free pig kidney endothelial cell line; DMEM: Dulbecco's modified eagle's medium; MTT: 3-(4,5dimethyithiazol-2-yl)-2,5-diphenyltetrazolium bromide; CPE: Cytopathologic effect; CR: Cytopathic ratio; MNTC: Maximum no-cytotoxic concentration; MSC: The maximum solubility concentration; $\mathrm{CC}_{50}$ : $50 \%$ cytotoxic concentration; $\mathrm{TCID}_{50}$ : 50\% tissue culture infective dose; qPCR: Real time quantitative PCR; ROS: Reactive oxygen species; MMP: Mitochondrial membrane potential

\section{Acknowledgements}

We thank Prof. Jiang (Nanjing Agricultural University) for his assistance in the PCV2.

Authors' contributions

$Y X, J Z, N S$ and $H L$ designed all the experiments. YX and JZ performed the MTT experiments, GPCR and Western blot assays. YS, KF, and WY performed the Flow cytometer assays. YX, PS, NS, XZ and JG wrote the manuscript. All authors read and approved the final manuscript.

\section{Funding}

This work was supported by National key research and development program (Grant No. 2017YFD0501500). The funding body had a role in the design of the study, collection, analysis, and interpretation of data or in the writing of this manuscript.

\section{Availability of data and materials}

The datasets used and analysed during the current study are available from the corresponding author on reasonable request.

Ethics approval and consent to participate

The experiment was performed in according to the experiment operational guideline of Shanxi province, China.

Consent for publication

Not applicable.

Competing interests

All authors declared no competing conflict of interest. 


\section{Author details}

${ }^{1}$ College of Veterinary Medicine, Shanxi Agricultural University, Taigu, Shanxi 030801, China. ${ }^{2}$ Laboratory Animal Center, Shanxi Agricultural University, Taigu 030801, Shanxi, China. ${ }^{3}$ Department of Veterinary Pathobiology, Schubot Exotic Bird Health Center, Texas A\&M University, College Station, Texas, TX 77843, USA. ${ }^{4}$ Medical Research Council (MRC) Centre for Inflammation Research, Queen's Medical Research Institute, The University of Edinburgh, Edinburgh EH16 4TJ, UK.

Received: 28 April 2020 Accepted: 11 September 2020

Published online: 18 September 2020

\section{References}

1. Ellis J, Clark E, Haines D, West K, Krakowka S, Kennedy S, Allan GM. Porcine circovirus-2 and concurrent infections in the field. Vet Microbiol. 2004;98(2): 159-63.

2. Meng XJ. Spread like a wildfire-the omnipresence of porcine circovirus type 2 (PCV2) and its ever-expanding association with diseases in pigs. Virus Res. 2012;164(1-2):1-3.

3. Nawagitgul P, Morozov I, Bolin SR, Harms FA, Sorden SD, Paul PS. Open reading frame 2 of porcine circovirus type 2 encodes a major capsid protein. J Gen Virol. 2000;81(9):2281-7.

4. Kiupel M, Stevenson GW, Galbreath EJ, North A, HogenEsch H, Mittal SK. Porcine circovirus type 2 (PCV2) causes apoptosis in experimentally inoculated BALB/C mice. BMC Vet Res. 2005;1 (1):7-15.

5. Lv YJ, Dai L, Han HL, Zhang SX. PCV2 induces apoptosis and modulates calcium homeostasis in piglet lymphocytes in vitro. Res Vet Sci. 2012;93(3): 1525-30.

6. Zhou YS, Qi BZ, Gu BZ, Xu F, Du HH, Li XL, Fang WH. Porcine circovirus 2 deploys PERK pathway and GRP78 for its enhanced replication in PK-15 cells. Viruses. 2016;8(2):56-72.

7. Zhang Y, Sun R, Geng S, Shan Y, Li X. Porcine circovirus type 2 induces ORF3-independent mitochondrial apoptosis via perk activation and elevation of cytosolic calcium. J Virol. 2019;93(7):1784-800.

8. Wei L, Zhu Z, Wang J, Liu J. Activation of the phosphatidylinositol 3-kinase/ AKT signaling pathway during porcine circovirus type 2 infection facilitates cell survival and viral replication. J Virol. 2012;86(24):13589-97.

9. Wei L, Zhu Z, Wang J, Zhang C, Quan R, Yan X. Regulatory role of ASK1 in porcine circovirus type 2-induced apoptosis. Virology. 2013;447(1-2):285-91.

10. Zhai SL, Chen SN, Xu ZH, Tang MH, Wang FG, Li XJ, Sun BB, Deng SF, Hu J, Lv DH, Wen XH, Yuan J, Luo ML, Wei WK. Porcine circovirus type 2 in China: an update on and insights to its prevalaence and control. Virol J. 2014;11(1): 88-99.

11. Beach NM, Meng XJ. Efficacy and future prospects of commercially available and experimental vaccines against porcine circovirus type 2 (PCV2). Virus Res. 2012;164(1-2):33-42.

12. Cinatl J, Morgenstern B, Bauer G, Chandra PP, Rabenau H, Doerr HW. Glycyrrhizin, an active component of liquorice roots, and replication of sarsassociated coronavirus. Lancet. 2003;361(9374):2045-6.

13. Xu WS, Zhao KK, Miao XH, Ni W, Cai X, Zhang RQ, Wang JX. Effect of oxymatrine on the replication cycle of hepatitis B virus in vitro. World J Gastroenterol. 2010;16(16):2028-37.

14. Chen C, Zuckerman DM, Brantley S, Sharpe M, Childress K, Hoiczyk E, Pendleton AR. Sambucus Nigra extracts inhibit infectious bronchitis virus at an early point during replication. BMC Vet Res. 2014;16(1):10-24.

15. Hakobyan A, Arabyan E, Avetisyan A, Abroyan L, Hakobyan L, Zakaryan H. Apigenin inhibits African swine fever virus infectionin vitro. Arch Virol. 2016; 61(12):3445-53.

16. Cheng W, Ren J, Huang Q, Long H, Jin H, Zhang L, Liu H, Van OL, Lin W. Pregnane steroids from a gorgonian coral subergorgia suberosa with antiflu virus effects. Steroids. 2016;108:99-104.

17. Cheng J, Sun N, Zhao X, Niu L, Song M, Sun Y, Jiang J, Guo J, Bai Y, He J, Li $H$. In vitro screening for compounds derived from traditional Chinese medicines with antiviral activities against porcine reproductive and respiratory syndrome virus. J Microbiol Biotechnol. 2013;23(8):1076-83.

18. Sun Y, Song M, Niu L, Bai X, Li H. Antiviral effects of the constituents derived from Chinese herb medicines on infectious bursal disease virus. Pharm Biol. 2013;51(9):1137-43.

19. Sun N, Yu T, Zhao JX, Sun YG, Jiang JB, Duan ZB, Wang WK, Hu YL, Lei HM, $\mathrm{Li} \mathrm{HQ}$. Antiviral activities of natural compounds derived from traditional
Chinese medicines against porcine circovirus type 2 (PCV2). Biotechnol Bioproc E. 2015;20(1):180-7.

20. Wang $Z W$, Sun $N, W u C H$, Jiang JB, Bai YS, Li HQ. In vitro antiviral activity and underlying molecular mechanisms of dipotassium glycyrrhetate against porcine reproductive and respiratory syndrome virus. Antivir Ther. 2013; 18(8):997-1004.

21. Sun Y, Niu L, Song M, Zhao X, Sun N, He JP, Wu CH, Jiang JB, Bai YS, Guo $\mathrm{JH}$, Li HQ. Screening compounds of Chinese medicinal herbs anti-marek's disease virus. Pharm Biol. 2014;52(7):841-7.

22. Zhang JQ, Gu YL, Wu CH, Ma HL, He JP, Bai YS, Li HQ. Effects of sodium tanshinone IIA sulfonate against Marek's disease virus in experimentally infected chickens. Int J Biol Macromol. 2013;58:258-62.

23. Li E, Sun N, Zhao JX, Sun YG, Huang JG, Lei HM, Guo JH, Hu YL, Wang WK, Li $\mathrm{HQ}$. In vitro evaluation of antiviral activity of tea seed saponins against porcine reproductive and respiratory syndrome virus. Antivir Ther. 2015;20(7):743-52.

24. Sun N, Wang ZW, Wu CH, Li E, He JP, Wang SY, Hu YL, Lei HM, Li HQ. Antiviral activity and underlying molecular mechanisms of Matrine against porcine reproductive and respiratory syndrome virus in vitro. Res Vet Sci. 2014;96(2):323-7.

25. Sun N, Sun PP, Lv HP, Sun YG, Guo JH, Wang ZR, Luo TT, Wang SY, Li HQ. Matrine displayed antiviral activity in porcine alveolar macrophages coinfected by porcine reproductive and respiratory syndrome virus and porcine circovirus type 2. Sci Rep. 2016;6(1):24401-14.

26. Furusawa $\mathrm{S}, \mathrm{Wu} \mathrm{JH}$. The effects of biscoclaurine alkaloid cepharanthine on mammalian cells: implications for cancer, shock, and inflammatory diseases. Life Sci. 2007:80(12):1073-9.

27. Zhou YB, Wang YF, Zhang Y, Zheng LY, Yang XA, Wang N, Jiang JH, Ma F, Yin DT, Sun CY, Wang QD. In vitro activity of cepharanthine hydrochloride against clinical wild-type and lamivudine-resistant hepatitis Bvirus isolates. Eur J Pharmacolo. 2012;683(1-3):10-5.

28. Okamoto M, Okamoto T, Baba M. Inhibition of human immunodeficiency virus type 1 replication by combination of transcription inhibitor K-12 and other antiretroviral agents in acutely and chronically infected cells. Antimicrob Agents Chemother. 1999;43(3):492-7.

29. Suresh MV, Wagner MC, Rosania GR, Stringer KA, Reddy RC. Pulmonary administration of a water-soluble curcumin complex reduces severity of acute lung injury. Am J Respir Cell Mol Biol. 2012;47(3):280-7.

30. Dai J, Gu L, Su Y, Wang Q, Zhao Y, Chen XX, Deng HX, Li W, Wang GF, Li KS. Inhibition of curcumin on influenza a virus infection and influenzal pneumonia, via, oxidative stress, TLR2/4, p38/JNK MAPK and NF-KB pathways. Int Immunopharmacol. 2018;54:177-87.

31. Umar S, Shah MA, Munir MT, Yaqoob M, Fiaz M, Anjum S, Ouzouaia M, Younus M, Nisa Q, lqbal M, Umar W. Synergistic effects of thymoquinone and curcumin on immune response and anti-viral activity against avian influenza virus (H9N2) in turkeys. Poult Sci. 2016;95(7):1513-20.

32. Padilla SL, Rodríguez A, Gonzales MM, Gallego GJ, Castano OJ. Inhibitory effects of curcumin on dengue virus type 2-infected cellsin vitro. Arch Virol. 2014;59(3):573-9.

33. Kim KJ, Kim KH, Kim HY, Cho HK, Sakamoto N, Cheong JH. Curcumin inhibits hepatitis $C$ virus replication via suppressing the AKT-SREBP-1 pathway. FEBS Lett. 2010;584(4):707-12.

34. Lin C, Gu J, Wang H, Zhou J, Li J, Wang S, Jin Y, Liu C, Liu J, Yang H, Jiang P, Zhou J. Caspase-dependent apoptosis induction via viral protein ORF4 of porcine circovirus 2 binding to mitochondrial adenine nucleotide translocase 3. J Virol. 2018;92(10):e00238-56.

35. Chen HL, Yang J, Fu YF, Meng XN, Hu TJ. Effect of total flavonoids of Spatholobus suberectus Dunn on PCV2 induced oxidative stress in raw 264. 7 cells. BMC complement. Altern Med. 2017;17(1):244-53.

36. Chen XX, Ren F, Hesketh J, Shi XL, Li JX, Gan F, Huang KH. Reactive oxygen species regulate the replication of porcine circovirus type 2 via NF-KB pathway. Virology. 2012;426(1):66-72.

37. Adeyemi RO, Landry S, Davis ME, Weitzman MD, Pintel DJ. Parvovirus minute virus of mice induces a DNA damage response that facilitates viral replication. PLoS Pathog. 2010;6(10):e1001141-53.

38. Su ZJ, Wei YY, Yin D, Shuai XH, Zeng Y, Hu TJ. Effect of Sophora Subprosrate Polysaccharide on oxidative stress induced by PCV2 infection in RAW264.7 cells. Int J Biol Macromol. 2013;62:457-64.

\section{Publisher's Note}

Springer Nature remains neutral with regard to jurisdictional claims in published maps and institutional affiliations. 